\title{
Cytogenetic No Response
}

National Cancer Institute

\section{Source}

National Cancer Institute. Cytogenetic No Response. NCI Thesaurus. Code C123581.

No change in abnormal karyotype, based on pre-defined thresholds. 